\title{
Missense Variants in Plakophilin-2 in Arrhythmogenic Right Ventricular Cardiomyopathy Patients - Disease-Causing or Innocent Bystanders?
}

\author{
Alex Hørby Christensen ${ }^{a, d}$ Marianne Benn ${ }^{b, d}$ Anne Tybjærg-Hansen ${ }^{c}$ \\ Stig Haunso ${ }^{a}$, b, d, e Jesper Hastrup Svendsen ${ }^{a, d}$, e \\ ${ }^{a}$ Department of Cardiology, ${ }^{\mathrm{b}}$ The Laboratory for Molecular Cardiology, and ${ }^{\mathrm{C}}$ Department of Clinical Biochemistry, \\ Rigshospitalet, Copenhagen University Hospital, ${ }^{\mathrm{d}}$ The Danish National Research Foundation Centre for Cardiac \\ Arrhythmia, and ${ }^{\text {DDepartment }}$ of Surgery and Medicine, Faculty of Health Sciences, University of Copenhagen, \\ Copenhagen, Denmark
}

\section{For editorial comment see p. 145}

\section{Key Words}

Arrhythmogenic right ventricular cardiomyopathy •

Genetics · Desmosome · Cardiomyopathy

\begin{abstract}
Objectives: Mutations in genes encoding desmosomal proteins have been linked to arrhythmogenic right ventricular cardiomyopathy/dysplasia (ARVC/D). We hypothesized that a Scandinavian ARVC/D population would have a different spectrum of plakophilin-2 (PKP2) mutations and that some of the reported missense mutations may not be pathogenic. Methods: We screened 53 unrelated patients fulfilling Task Force criteria for ARVC/D for mutations in PKP2 by direct sequencing. Results: Seven different mutations were identified: two insertion/deletions (E329fsX352, P401fsX406), 1 splice site (2146-2A>T), 1 non-sense (R79X) and 4 missense mutations (Q62K in 2 patients, G489R, G673V) of undeterminable pathogeneity. None of these mutations was present in 650 controls. Five of the mutations were novel. Seven patients carried reported missense mutations (D26N, S140F, V587I); however, these mutations were identified in our
\end{abstract}

healthy controls, although at a lower frequency. Evaluation of all reported missense mutations in PKP2 showed unclear pathogeneity of several reported mutations. Conclusions: Fifteen percent of Danish ARVC/D patients carried PKP2 mutations. Our finding of reported disease-causing mutations at a low frequency among healthy controls suggests that these variants are disease modifying but not directly disease causing. We recommend conservative interpretation of missense variants in PKP2, functional characterization and largescale sequencing to clarify normal variation in the gene.

Copyright $\odot 2009$ S. Karger AG, Basel

\section{Introduction}

Arrhythmogenic right ventricular cardiomyopathy/ dysplasia (ARVC/D) is an inherited cardiomyopathy characterized by predominantly right ventricular involvement. Clinical presentation is mainly due to ventricular arrhythmias and symptoms may include palpitations, dizziness, syncope and sudden cardiac death. Pathoanatomical findings consist of atrophy of the car-

\section{KARGER}

Fax +4161306 1234 E-Mail karger@karger.ch www.karger.com
(C) 2009 S. Karger AG, Basel

$0008-6312 / 10 / 1152-0148 \$ 26.00 / 0$

Accessible online at:

www.karger.com/crd
Jesper Hastrup Svendsen, MD, DMSc

Department of Cardiology, Section 2013, Rigshospitalet

Blegdamsvej 9

DK-2100 Copenhagen (Denmark)

Tel. +45 3545 2817, Fax +45 3538 3186, E-Mail jesper.hastrup.svendsen@ rh.regionh.dk 
diac myocytes and fibrofatty infiltrations. The disease is progressive, and left ventricular involvement may occur at various stages [1]. Recommended treatment for prevention of sudden cardiac death is an implantable cardioverter-defibrillator (ICD).

The clinical diagnosis is based on a set of Task Force criteria [2] including functional and anatomical characteristics of the right ventricle, electrical abnormalities, and family history. The diagnosis is challenging and subjective due to the lack of a confirmatory test.

Several genes encoding desmosomal proteins have been associated with ARVC/D: plakoglobin (JUP) [3, 4], desmoplakin (DSP) [5, 6], plakophilin-2 (PKP2) [7-11], desmoglein-2 (DSG2) [12] and desmocollin-2 (DSC2) [13]. Of nondesmosomal genes, mutations in the cardiac $r y$ anodine receptor (RYR2) [14] and the regulatory elements of transforming growth factor $\beta$-3 (TGF $\beta 3$ ) [15] have been suggested as rare causes of ARVC/D. Recently, a gene of unknown function, TMEM43, has been shown to cause a variant form of ARVC/D with complete penetrance [16]. Except for JUP, the primary mode of inheritance is autosomal dominant with variable penetrance, but recessive forms have also been described for DSP [17], PKP2 [18] and DSC2 [19].

The discovery of a high proportion of ARVC/D patients with mutations in desmosomal genes introduces genetic testing as an important tool assisting the clinician. In the early phases of the disease, the Task Force criteria lack sensitivity, and benign causes of right-sided ventricular tachycardia are the main differential diagnoses. Often, considerations about ICD implantation are relevant with risk of stigmatization, device complications and necessity for regular device replacements. In this context, genetic testing may be an invaluable aid with a positive molecular genetic finding effectively differentiating ARVC/D from other causes of right-sided ventricular tachycardia. In the handling of family members, clinical evaluation is often hampered by incomplete and agedependent penetrance and variable phenotype. Genetic testing of relatives to mutation carriers enables the clinician to provide reassurance and exclude noncarriers from lifelong clinical follow-up. As promising as genetic testing is as a supplement in patient and family handling, the need for definitive pathogeneity of the identified mutations is crucial for correct treatment and follow-up.

Variable frequencies of $P K P 2$ and differences in the spectrum of mutations have been reported in different populations. As a Scandinavian population has never been screened, we found it of interest to screen a Danish ARVC/D population and hypothesized that Danes would have a different spectrum of PKP2 mutations. We also hypothesized that some of the missense mutations reported as disease causing were benign and wished to screen a large number of healthy controls for all found mutations.

\section{Methods}

\section{Study Population}

The patient population consisted of 53 unrelated white patients (31 men) fulfilling the Task Force criteria for ARVC/D. Patients were identified at Rigshospitalet, Copenhagen University Hospital, Denmark, which is a tertiary referral center. The population consisted of all identified unrelated patients at the center, except 4 patients who declined genetic testing. A digital ECG, blood sample for genetic analysis, personal medical and family history were obtained from all patients. Results of previously performed diagnostic testing including 2-D echocardiogram, Holter monitoring, stress ECG, signal-averaged ECG $(n=36)$, magnetic resonance imaging $(n=26)$, right ventriculography $(n=50)$ and endomyocardial biopsy $(n=48)$ were registered. Ten patients with some ARVC/D characteristics but not fulfilling Task Force criteria were also screened, but since no mutations were found in these patients, they were omitted from further analysis. The study was approved by the local ethics committee (KF01-152/04), followed the Helsinki Declaration II, and all participants gave written informed consent prior to inclusion in the study.

\section{Genotyping and Sequence Alignment}

DNA was extracted from peripheral blood using standard techniques. Polymerase chain reaction (PCR) amplification was performed of all PKP2 transcript variant 2b (NM_004572.3) exons and flanking intron sequences. Primers and PCR conditions are available on request. Bidirectional sequencing was performed using the dideoxy chain-termination method. Variants with a frequency of less or above $1 \%$ were defined as a mutation or a polymorphism, respectively. Protein sequence alignments were done as multisequence alignment with ClustalW2 (EMBL-EBI) using the following reference sequences: Homo sapiens (ENSP00000070846), Pan troglodytes (ENSPTRP00000050160), Macaca mulatta (ENSMMUP00000000801), Bos taurus (ENSBTAP00000003435), Canis familiaris (ENSCAFP00000015415), Mus musculus (ENSMUSP00000036890) and Gallus gallus (ENSGALP00000021029). Potential functional effect of all novel or reported missense mutations in PKP2 were evaluated by in silico predictions using three different algorithms: Polymorphism Phenotyping (PolyPhen) [20], PANTHER [21] and Sorting Intolerant from Tolerant (SIFT) [22] algorithms. All three algorithms use multisequence alignment and scoring of the physical properties of the involved amino acid in their predictions. Prediction of alternative splice sites was done using the Alternative Splice Site Predictor [23]. All predictions were done with standard parameters and cutoff values.

For all novel or missense mutations, 650 healthy controls (1,300 alleles) were genotyped using Taqman assays (Applied Biosystems, Calif., USA) except for the insertion, deletion and $1465 \mathrm{G}>\mathrm{A}$ mutation where controls were screened using a Light- 
Table 1. Clinical characteristics of the study population

\begin{tabular}{llc}
\hline Age at onset of symptoms, years (range) & & $35(2-62)$ \\
Males & & $31 / 53(58)$ \\
Reduced left ventricular function & & $10 / 53(19)$ \\
Family history & Major & $3 / 53(6)$ \\
& Minor & $8 / 53(15)$ \\
Abnormal depolarization & Major & $18 / 53(34)$ \\
& Minor & $17 / 53(32)$ \\
Abnormal repolarization & Minor & $25 / 53(47)$ \\
Arrhythmia & Minor & $47 / 53(89)$ \\
Structural/functional abnormality & Major & $11 / 53(21)$ \\
$\quad$ of the right ventricle & Minor & $27 / 53(51)$ \\
Tissue characteristics & Major & $29 / 53(55)$ \\
& &
\end{tabular}

Major = Major criteria fulfilled; minor $=$ minor criteria fulfilled. Figures in parentheses indicate percentages.

Scanner high-resolution melting curve analysis system (Idaho Technology, Utah, USA). The control population consisted of anonymous, self-reported healthy individuals from the general population. Forty-seven percent of the controls were men. Positive controls were sequenced for confirmation.

\section{Statistical Aspects}

Comparison of clinical features between patients with and without a PKP2 mutation and comparison of the incidence of the D26N, S140F and V587I mutations between ARVC/D patients and healthy controls were done with Fisher's exact two-tailed probability test. A p value of less than 0.05 was considered significant.

\section{Results}

\section{Clinical Characterization of the Study Population}

Clinical characterization of the study population is summarized in table 1 . None of the patients had ischemic heart disease, significant valvular heart disease, or diabetes. Six patients were treated for hypertension. Ten patients had reduced left ventricular function (ejection fraction below 55\%) but only 1 had severe impairment with an ejection fraction of $25 \%$.

\section{PKP2 Mutations and Evolutionary Conservation}

In the 53 screened patients, we identified 7 different heterozygous mutations in 8 patients. None of these mutations were present in the controls. Five of the mutations were novel. Of the reported mutations, 4 were missense mutations, 1 a non-sense, 2 insertion/deletions, and 1 was a splice site mutation. Details regarding the identified mutations are summarized in table 2 .
The E329fsX352 and P401fsX406 mutations both cause a frameshift that introduces a premature stop codon and terminates translation of a substantial part of the protein. The R79X mutation terminates translation in exon 2 and the product of this mutant allele is missing all 10 armadillo repeats. The $2146-2 \mathrm{~A}>\mathrm{T}$ splice site mutation is predicted to abolish the highly conserved splice acceptor site of intron 10 and introduces a cryptic splice acceptor site further downstream.

Four patients carried 3 different missense mutations. Two unrelated patients had the Q62K mutation and 1 had the G673V mutation. Both mutations affect highly conserved amino acids (table 3 ) but without a substantial change in polarity of the involved amino acids. One of the Q62K carriers had a clinically affected brother who did not carry the mutation. The patient with the G673V mutation also had the V587I mutation (see below) and S70I polymorphism. One patient carried the G489R mutation located in exon 6 , which causes a change in amino acid polarity, and is located in the unconserved 44 residue insertion unique to plakophilin-2 isoform $2 \mathrm{~b}$.

Seven patients carried missense mutations previously reported as disease causing (table 4); however, these mutations were present in our control population $(n=650)$. The previously reported D26N and V587I mutations affect highly conserved regions (table 3 ) but without a substantial change in polarity of the involved amino acid. The S140F mutation causes a severe change in the properties of the amino acid involved, but the region is not highly conserved, and phenylalanine exists in another species in the orthologous alignment. Two families carrying the S140F mutation did not show a genotype-phenotype correlation. For the other families, no family members were available for genetic testing. One of the patients carrying the D26N mutation also had the T338A mutation (see below).

The following novel mutation was present in both patients and controls: T338A (1012A>G; 1 patient, 1 control) and the following previously reported polymorphisms were found: E58D (174G $>$ T; 1 patient), S70I (209G > T; 3 patients), L366P (1097T>C; 9 heterozygous, 5 homozygous patients) and I531S (1592T >C; 1 patient).

\section{Predicted Effect of Variants}

The predicted effects of all reported missense mutations using 3 different algorithms are summarized in table 3. Of the 14 analyzed mutations, the PolyPhen algorithm predicted 4 to be benign, 4 to be possibly damaging and 6 to be probably damaging. The PANTHER algorithm did not produce valid predictions for the first 5 
Table 2. Overview of $P K P 2$ mutations in the study population

\begin{tabular}{|c|c|c|c|c|c|c|c|c|}
\hline $\begin{array}{l}\text { Patient } \\
\text { No. }\end{array}$ & Exon & Mutation & AA substitution & $\begin{array}{l}\text { Change in } \\
\text { AA polarity }\end{array}$ & Type of mutation & Domain & Novel & Comments \\
\hline 1,2 & 1 & $184 \mathrm{C}>\mathrm{A}$ & Q62K & - & missense & N-term & - & UP \\
\hline 3 & 2 & $235 \mathrm{C}>\mathrm{T}$ & R79X & & nonsense & N-term & - & \\
\hline 4 & 3 & 983_984insGG & E329fsX352 & & insertion; frameshift & N-term & + & \\
\hline 5 & 5 & 1202_1209delTGCAGCTC & P401fsX406 & & deletion; frameshift & Arm2 & + & \\
\hline 6 & 6 & $1465 \mathrm{G}>\mathrm{A}$ & G489R & + & missense & Alu & + & UP \\
\hline 7 & 10 & $2018 \mathrm{G}>\mathrm{T}$ & G673V & - & missense & Arm7 & + & UP \\
\hline 8 & 11 & $2146-2 \mathrm{~A}>\mathrm{T}$ & mutant splice product & & splice site & Arm8 & + & \\
\hline
\end{tabular}

$\mathrm{AA}=\mathrm{Amino}$ acid $; \mathrm{Alu}=\mathrm{Alu}$ repeat located between armadillo repeat 3 and $4 ; \mathrm{Arm}=$ armadillo repeat motif; $\mathrm{N}$-term $=\mathrm{N}$-terminal part of the protein; UP = undeterminable pathogeneity. Patient numbers refer to patient numbers in table 5.

Table 3. Sequence alignment and in silico predictions of all reported missense mutations in PKP2

\begin{tabular}{|c|c|c|c|c|c|c|c|c|c|c|c|c|c|}
\hline $\begin{array}{l}\text { AA } \\
\text { substitution }\end{array}$ & $\begin{array}{l}\text { Nucleotide } \\
\text { substitution }\end{array}$ & $\begin{array}{l}\text { Change in } \\
\text { AA polarity }\end{array}$ & $\begin{array}{l}H . \\
\text { sapiens }\end{array}$ & $\begin{array}{l}P . \\
\text { troglodytes }\end{array}$ & $\begin{array}{l}\text { M. } \\
\text { mulatta }\end{array}$ & $\begin{array}{l}\text { B. } \\
\text { taurus }\end{array}$ & $\begin{array}{l}\text { C. } \\
\text { familiaris }\end{array}$ & $\begin{array}{l}\text { M. } \\
\text { musculus }\end{array}$ & $\begin{array}{l}\text { G. } \\
\text { gallus }\end{array}$ & $\begin{array}{l}\text { Poly- } \\
\text { Phen }\end{array}$ & PANTHER & SIFT & References \\
\hline $\mathrm{D} 26 \mathrm{~N}$ & $76 \mathrm{G}>\mathrm{A}$ & - & $\mathrm{D}$ & $\mathrm{D}$ & $\mathrm{D}$ & $\mathrm{D}$ & $\mathrm{D}$ & $\mathrm{D}$ & $\mathrm{D}$ & $\mathrm{PD}$ & - & $\mathrm{D}$ & {$[10], \mathrm{OF}$} \\
\hline Q59L & $176 \mathrm{~A}>\mathrm{T}$ & + & Q & Q & Q & Q & Q & Q & Q & D & - & D & [11] \\
\hline Q62K & $184 \mathrm{C}>\mathrm{A}$ & - & Q & Q & Q & Q & Q & Q & Q & $\mathrm{PD}$ & - & $\mathrm{D}$ & {$[10,11]$, OF } \\
\hline S140F & $419 \mathrm{C}>\mathrm{T}$ & + & S & S & S & F & S & S & $\mathrm{T}$ & B & - & B & {$[7-9,30]$, OF } \\
\hline T338A & $1012 A>G$ & + & $\mathrm{T}$ & $\mathrm{T}$ & S & $\mathrm{T}$ & $\mathrm{T}$ & V & $\mathrm{T}$ & B & - & B & OF \\
\hline F424S & $1271 \mathrm{~T}>\mathrm{C}$ & + & $\mathrm{F}$ & $\mathrm{F}$ & $\mathrm{F}$ & $\mathrm{F}$ & $\mathrm{F}$ & $\mathrm{F}$ & $\mathrm{F}$ & $\mathrm{D}$ & $\mathrm{D}$ & D & {$[7,9]$} \\
\hline G489R & $1465 \mathrm{G}>\mathrm{A}$ & + & G & G & S & - & G & - & - & B & B & B & OF \\
\hline V587I & $1759 \mathrm{G}>\mathrm{A}$ & - & V & V & V & V & V & V & V & B & $\mathrm{U}$ & D & [31], OF \\
\hline N613K & $1839 \mathrm{C}>\mathrm{G}$ & - & $\mathrm{N}$ & $\mathrm{N}$ & $\mathrm{N}$ & $\mathrm{N}$ & $\mathrm{N}$ & $\mathrm{N}$ & $\mathrm{N}$ & D & $\mathrm{D}$ & $\mathrm{D}$ & [11] \\
\hline S615F & $1844 \mathrm{C}>\mathrm{T}$ & + & S & S & S & S & S & S & S & D & $\mathrm{D}$ & D & {$[7,8]$} \\
\hline K654Q & $1960 A>C$ & - & K & $\mathrm{K}$ & $\mathrm{K}$ & $\mathrm{K}$ & K & $\mathrm{K}$ & K & PD & $\mathrm{D}$ & D & [7] \\
\hline G673V & $2018 \mathrm{G}>\mathrm{T}$ & - & G & G & G & G & G & G & G & $\mathrm{D}$ & $\mathrm{D}$ & D & OF \\
\hline S688P & $2062 \mathrm{~T}>\mathrm{C}$ & + & S & S & S & S & S & S & S & PD & $\mathrm{D}$ & D & {$[10]$} \\
\hline C796R & $2386 \mathrm{~T}>\mathrm{C}$ & + & $\mathrm{C}$ & $\mathrm{C}$ & $\mathrm{C}$ & $\mathrm{C}$ & $\mathrm{C}$ & $\mathrm{C}$ & $\mathrm{C}$ & $\mathrm{D}$ & $\mathrm{D}$ & $\mathrm{D}$ & [7] \\
\hline
\end{tabular}

$\mathrm{B}=$ Benign; $\mathrm{PD}=$ possibly damaging; $\mathrm{D}$ = probably damaging; $\mathrm{OF}=$ our findings; $\mathrm{U}=$ unknown effect.

Table 4. Frequency of reported missense mutations in ARVC/D patients and healthy controls

\begin{tabular}{llllll}
\hline Exon & $\begin{array}{l}\text { Nucleotide } \\
\text { substitution }\end{array}$ & $\begin{array}{l}\text { Amino acid } \\
\text { substitution }\end{array}$ & $\begin{array}{l}\text { Among ARVC/D } \\
\text { patients }\end{array}$ & $\begin{array}{l}\text { Among } \\
\text { controls }\end{array}$ & $\mathrm{p}$ \\
\hline 1 & $76 \mathrm{G}>\mathrm{A}$ & $\mathrm{D} 26 \mathrm{~N}$ & $3 / 53(5.7)$ & $9 / 650(1.4)$ & 0.05 \\
3 & $419 \mathrm{C}>\mathrm{T}$ & S140F & $3 / 53(5.7)$ & $5 / 650(0.8)$ & 0.02 \\
8 & $1759 \mathrm{G}>\mathrm{A}$ & V587I & $1 / 53(1.9)$ & $3 / 650(0.5)$ & 0.27 \\
\hline
\end{tabular}

$\mathrm{p}$ value by comparison with Fisher's exact test. Figures in parentheses indicate percentages. 
Table 5. Clinical characteristics of $P K P 2$ mutation carriers according to Task Force criteria

\begin{tabular}{|c|c|c|c|c|c|c|c|c|c|}
\hline $\begin{array}{l}\text { Patient } \\
\text { No. }\end{array}$ & Sex & $\begin{array}{l}\text { Age at onset } \\
\text { of symptoms } \\
\text { years }\end{array}$ & $\begin{array}{l}\text { Family } \\
\text { history }\end{array}$ & $\begin{array}{l}\text { Abnormal } \\
\text { depolarization }\end{array}$ & $\begin{array}{l}\text { Abnormal } \\
\text { repolarization }\end{array}$ & Arrhythmia & $\begin{array}{l}\text { Structural/functional } \\
\text { abnormality of the } \\
\text { right ventricle }\end{array}$ & $\begin{array}{l}\text { Tissue } \\
\text { characteristics }\end{array}$ & $\begin{array}{l}\text { Criteria } \\
\text { (major/minor) }\end{array}$ \\
\hline 1 & $\mathrm{~F}$ & 28 & & major & & minor & minor & NA & $1 / 2$ \\
\hline 2 & $\mathrm{M}$ & 35 & minor & & minor & minor & minor & & $0 / 4$ \\
\hline 3 & M & 24 & & major & minor & minor & & NA & $1 / 2$ \\
\hline 4 & $\mathrm{~F}$ & AS & major & & & & minor & major & $2 / 1$ \\
\hline 5 & $\mathrm{~F}$ & 42 & & & minor & minor & major & & $1 / 2$ \\
\hline 6 & $\mathrm{~F}$ & 39 & & minor & & minor & major & & $1 / 2$ \\
\hline 7 & $\mathrm{M}$ & AS & minor & major & minor & & & & $1 / 2$ \\
\hline 8 & $\mathrm{M}$ & 36 & & & minor & minor & major & NA & $1 / 2$ \\
\hline
\end{tabular}

AS = Asymptomatic minor $=$ minor criteria fulfilled; major $=$ major criteria fulfilled; NA = not available

listed mutations, but of the remaining 9 mutations 1 was predicted to be benign, 7 to be damaging and 1 of unknown function. The SIFT algorithm predicted 3 to be benign and 11 to be damaging.

\section{Genotype-Phenotype Correlation}

Six of the mutation carriers were referred to our center for further evaluation due to symptomatic ventricular tachycardia. The remaining 2 patients were referred for evaluation due to ARVC/D-related deaths in the families several years prior to referral. The clinical features of the mutation carriers are summarized in table 5. Comparison of clinical data between the PKP2-positive and the PKP2negative group showed no significant difference with regard to age at symptom onset (34 vs. 36 years), right ventricular involvement, depolarization or repolarization abnormalities, documented ventricular arrhythmia or positive family history. None of the 8 mutation carriers had reduced left ventricular function compared to $10(0$ vs. $23 \%, \mathrm{p}=0.32$ ) of the PKP2-negative patients. Seven of the 8 mutation carriers had an ICD implanted, which was not significantly different from the noncarriers.

\section{Discussion}

Our study showed that $15 \%$ of Danish ARVC/D patients had mutations in PKP2 consisting of 4 truncating and 4 missense mutations. The pathogeneity of our reported missense mutations is, however, unclear. The geographical differences in PKP2 mutation frequencies may be caused by differences in ethnicity, patient selection, founder mutations, and limited sample sizes.
The R79X, E329fsX352, and P401fsX406 mutations identified in our study population all introduce a premature stop codon. The transcripts of these 3 mutant alleles are most likely degraded by non-sense-mediated mRNA decay [24]. If translated, the mutant transcripts would cause a truncated protein. Together with the 2146-2A $>\mathrm{T}$ splice site mutation, all 4 mutations result in functional haploinsufficiency.

Three different missense mutations were identified in 4 patients. A Q62K mutation occurred in a patient from a family with a high incidence of ARVC/D; however, the patient's brother, who is also clinically affected, does not carry the mutation. The G489R mutation located in exon 6 affects an Alu repeat [25] unique to the PKP2 isoform $2 b$. The function of this Alu repeat located between armadillo repeat 3 and 4 is unknown, and the significance of alternative transcripts in other species is not well characterized. No previous mutations have been reported in exon 6. The G673V mutation introduces a hydrophobic amino acid of a different size but with unchanged polarity. In conclusion, the pathogeneity of these 3 missense mutations (Q62K, G489R, G673V) cannot be established with certainty due to lack of change in amino acid polarity or location in a nonconserved region.

Our finding of several reported disease-causing missense mutations (D26N, S140F, V587I) in healthy controls raises questions about the pathogeneity of these mutations (D26N was labeled as an unclassified variant by the Dutch group [10]). In conjunction with orthologous alignment, properties of the involved amino acid and lack of genotype-phenotype correlation (S140F), it is not likely that these mutations are directly disease causing. The concern about the disease-causing effect of missense 
mutations in $P K P 2$ can be extended to several other reported missense mutations. Although not definitive evidence, in silico predictions of all reported missense mutations in PKP2 showed that several of the mutations were classified as possibly, rather than probably, damaging to the protein. Some inconsistencies existed but none of the 3 mutations present in our controls (D26N, S140F, V587I) was uniformly predicted to be detrimental.

The majority of the reported mutations in PKP2 are non-sense and frameshift mutations with haploinsufficiency as the suggested molecular disease mechanism. The overrepresentation (table 4) of the D26N, S140F and V587I mutations in ARVC/D patients compared with controls may reflect that these mutations are susceptibility mutations or have a disease-modifying role. The concept of increased susceptibility associated with certain mutations is consistent with a recent report showing the V56M variant in DSG2 (suggested as disease causing in ARVC/D [26]) as a predisposing factor for dilated cardiomyopathy, but also present in healthy controls [27]. Although speculative, the ARVC/D phenotype may be a result of a missense PKP2 mutation in conjunction with other genetic, epigenetic or environmental factors (e.g. myocarditis or exercise). Two patients carried two mutations each (V587I/G673V and D26N/T338A, respectively). These findings suggest that multiple mutations may have a synergistic negative effect on protein function.

The classification of a genetic variant as disease causing or benign is a known challenge in human genetics. Evaluation of amino acid properties, evolutionary conservation, cosegregation analysis in families, absence in a control population, in silico predictions and functional characterization are tools in determining the pathogeneity. Expression systems for desmosomal mutations are evolving and have been described for DSP [28] and DSG2
[29]. These systems are complex and expensive, and due to the high number of private mutations it is currently not feasible that all reported mutations can be tested in such systems.

The aim of this study was to establish the prevalence of PKP2 mutations in a Scandinavian ARVC/D population, and genes coding for other desmosome proteins were not evaluated. Other limitations include selection bias to tertiary center, inability to detect large genomic insertions/deletions, uncertainties in prediction programs and limited cohort size. Due to the anonymous identity of our control population, no systematic clinical evaluation for ARVC/D was possible which would have been optimal. However, we find it highly unlikely that 17 (D26N, S140F and V587I carriers) out of 650 controls have concealed ARVC/D due to the rarity and genetic heterogeneity associated with the disease.

In conclusion, $15 \%$ of Danish ARVC/D patients have mutations in PKP2. Our finding of previously reported disease-causing missense mutations in healthy controls raises concerns about the pathogeneity of these mutations and suggests increased susceptibility or a diseasemodifying role. We recommend conservative evaluation of missense variants in ARVC/D patients, functional characterization and large-scale sequencing of healthy controls to clarify normal variation in PKP2.

\section{Acknowledgments}

This work was supported by grants from The Danish National Arrhythmia Research Foundation Centre for Cardiac Arrhythmia, Danish Cardiovascular Research Academy, The Research Council at the Heart Centre, Rigshospitalet, The Villadsen Family Foundation, Brødrene Hartmanns Foundation, and The John and Birthe Meyer Foundation.

\section{References}

1 Fontaine G, Fontaliran F, Hebert JL, Chemla D, Zenati O, Lecarpentier Y, Frank R: Arrhythmogenic right ventricular dysplasia. Annu Rev Med 1999;50:17-35.

-2 McKenna WJ, Thiene G, Nava A, Fontaliran F, Blomstrom-Lundqvist C, Fontaine G, Camerini F: Diagnosis of arrhythmogenic right ventricular dysplasia/cardiomyopathy. Task Force of the Working Group Myocardial and Pericardial Disease of the European Society of Cardiology and of the Scientific Council on Cardiomyopathies of the International Society and Federation of Cardiology. Br Heart J 1994;71:215-218.
- 3 McKoy G, Protonotarios N, Crosby A, Tsatsopoulou A, Anastasakis A, Coonar A, Norman M, Baboonian C, Jeffery S, McKenna WJ: Identification of a deletion in plakoglobin in arrhythmogenic right ventricular cardiomyopathy with palmoplantar keratoderma and woolly hair (Naxos disease). Lancet 2000;355:2119-2124.

4 Asimaki A, Syrris P, Wichter T, Matthias P, Saffitz JE, McKenna WJ: A novel dominant mutation in plakoglobin causes arrhythmogenic right ventricular cardiomyopathy. Am J Hum Genet 2007;81:964-973.
5 Rampazzo A, Nava A, Malacrida S, Beffagna G, Bauce B, Rossi V, Zimbello R, Simionati B, Basso C, Thiene G, Towbin JA, Danieli GA: Mutation in human desmoplakin domain binding to plakoglobin causes a dominant form of arrhythmogenic right ventricular cardiomyopathy. Am J Hum Genet 2002;71: 1200-1206.

-6 Bauce B, Basso C, Rampazzo A, Beffagna G, Daliento L, Frigo G, Malacrida S, Settimo L, Danieli G, Thiene G, Nava A: Clinical profile of four families with arrhythmogenic right ventricular cardiomyopathy caused by dominant desmoplakin mutations. Eur Heart J 2005;26:1666-1675. 
7 Gerull B, Heuser A, Wichter T, Paul M, Basson CT, McDermott DA, Lerman BB, Markowitz SM, Ellinor PT, MacRae CA, Peters S, Grossmann KS, Drenckhahn J, Michely B, Sasse-Klaassen S, Birchmeier W, Dietz R, Breithardt G, Schulze-Bahr E, Thierfelder L: Mutations in the desmosomal protein plakophilin-2 are common in arrhythmogenic right ventricular cardiomyopathy. Nat Genet 2004;36:1162-1164.

$\checkmark 8$ Syrris P, Ward D, Asimaki A, Sen-Chowdhry S, Ebrahim HY, Evans A, Hitomi N, Norman M, Pantazis A, Shaw AL, Elliott PM, McKenna WJ: Clinical expression of plakophilin-2 mutations in familial arrhythmogenic right ventricular cardiomyopathy. Circulation 2006;113:356-364.

$\checkmark 9$ Dalal D, Molin LH, Piccini J, Tichnell C, James C, Bomma C, Prakasa K, Towbin JA, Marcus FI, Spevak PJ, Bluemke DA, Abraham T, Russell SD, Calkins H, Judge DP: Clinical features of arrhythmogenic right ventricular dysplasia/cardiomyopathy associated with mutations in plakophilin-2. Circulation 2006;113:1641-1649.

-10 van Tintelen JP, Entius MM, Bhuiyan ZA, Jongbloed R, Wiesfeld AC, Wilde AA, van der Smagt J, Boven LG, Mannens MM, van Langen IM, Hofstra RM, Otterspoor LC, Doevendans PA, Rodriguez LM, van Gelder IC, Hauer RN: Plakophilin-2 mutations are the major determinant of familial arrhythmogenic right ventricular dysplasia/cardiomyopathy. Circulation 2006;113:1650-1658.

-11 Lahtinen AM, Lehtonen A, Kaartinen M, Toivonen L, Swan H, Widen E, Lehtonen E, Lehto VP, Kontula K: Plakophilin-2 missense mutations in arrhythmogenic right ventricular cardiomyopathy. Int J Cardiol 2008;126:92-100

-12 Pilichou K, Nava A, Basso C, Beffagna G, Bauce B, Lorenzon A, Frigo G, Vettori A, Valente M, Towbin J, Thiene G, Danieli GA, Rampazzo A: Mutations in desmoglein-2 gene are associated with arrhythmogenic right ventricular cardiomyopathy. Circulation 2006;113:1171-1179.

-13 Syrris P, Ward D, Evans A, Asimaki A, Gandjbakhch E, Sen-Chowdhry S, McKenna WJ: Arrhythmogenic right ventricular dysplasia/ cardiomyopathy associated with mutations in the desmosomal gene desmocollin-2. Am J Hum Genet 2006;79:978-984.
14 Tiso N, Stephan DA, Nava A, Bagattin A, Devaney JM, Stanchi F, Larderet G, Brahmbhatt B, Brown K, Bauce B, Muriago M, Basso C, Thiene G, Danieli GA, Rampazzo A: Identification of mutations in the cardiac ryanodine receptor gene in families affected with arrhythmogenic right ventricular cardiomyopathy type 2 (ARVD2). Hum Mol Genet 2001;10:189-194.

15 Beffagna G, Occhi G, Nava A, Vitiello L, Ditadi A, Basso C, Bauce B, Carraro G, Thiene G, Towbin JA, Danieli GA, Rampazzo A: Regulatory mutations in transforming growth factor-beta3 gene cause arrhythmogenic right ventricular cardiomyopathy type 1. Cardiovasc Res 2005;65:366-373.

16 Merner ND, Hodgkinson KA, Haywood AF, Connors S, French VM, Drenckhahn JD, Kupprion C, Ramadanova K, Thierfelder L, McKenna W, Gallagher B, Morris-Larkin L, Bassett AS, Parfrey PS, Young TL: Arrhythmogenic right ventricular cardiomyopathy type 5 is a fully penetrant, lethal arrhythmic disorder caused by a missense mutation in the TMEM43 gene. Am J Hum Genet 2008; 82:809-821.

17 Alcalai R, Metzger S, Rosenheck S, Meiner V, Chajek-Shaul T: A recessive mutation in desmoplakin causes arrhythmogenic right ventricular dysplasia, skin disorder, and woolly hair. J Am Coll Cardiol 2003;42:319-327.

18 Awad MM, Dalal D, Tichnell C, James C, Tucker A, Abraham T, Spevak PJ, Calkins H, Judge DP: Recessive arrhythmogenic right ventricular dysplasia due to novel cryptic splice mutation in PKP2. Hum Mutat 2006; 27:1157.

19 Simpson MA, Mansour S, Ahnood D, Kalidas K, Patton MA, McKenna WJ, Behr ER, Crosby AH: Homozygous mutation of desmocollin-2 in arrhythmogenic right ventricular cardiomyopathy with mild palmoplantar keratoderma and woolly hair. Cardiology 2008;113:28-34.

20 Sunyaev S, Ramensky V, Koch I, Lathe W 3rd, Kondrashov AS, Bork P: Prediction of deleterious human alleles. Hum Mol Genet 2001;10:591-597.

21 Thomas PD, Campbell MJ, Kejariwal A, Mi H, Karlak B, Daverman R, Diemer K, Muruganujan A, Narechania A: PANTHER: a library of protein families and subfamilies indexed by function. Genome Res 2003; 13: 2129-2141.

$\checkmark 22$ Ng PC, Henikoff S: Predicting deleterious amino acid substitutions. Genome Res 2001; 11:863-874.

$\checkmark 23$ Wang M, Marin A: Characterization and prediction of alternative splice sites. Gene 2006;366:219-227.
24 Mendell JT, Dietz HC: When the message goes awry: disease-producing mutations that influence mRNA content and performance. Cell 2001;107:411-414.

25 Bonné S, van Hegel J, Nollet F, Kools P, van Roy F: Plakophilin-3, a novel armadillo-like protein present in nuclei and desmosomes of epithelial cells. J Cell Sci 1999;112:22652276.

26 Syrris P, Ward D, Asimaki A, Evans A, SenChowdhry S, Hughes SE, McKenna WJ: Desmoglein-2 mutations in arrhythmogenic right ventricular cardiomyopathy: a genotype-phenotype characterization of familial disease. Eur Heart J 2007;28:581-588.

-27 Posch MG, Posch MJ, Geier C, Erdmann B, Mueller W, Richter A, Ruppert V, Pankuweit S, Maisch B, Perrot A, Buttgereit J, Dietz R, Haverkamp W, Ozcelik C: A missense variant in desmoglein-2 predisposes to dilated cardiomyopathy. Mol Genet Metab 2008;95: 74-80.

28 Yang Z, Bowles NE, Scherer SE, Taylor MD, Kearney DL, Ge S, Nadvoretskiy VV, DeFreitas G, Carabello B, Brandon LI, Godsel LM, Green KJ, Saffitz JE, Li H, Danieli GA, Calkins H, Marcus F, Towbin JA: Desmosomal dysfunction due to mutations in desmoplakin causes arrhythmogenic right ventricular dysplasia/cardiomyopathy. Circ Res 2006;99:646-655.

29 Pilichou K, Remme CA, Basso C, Campian ME, Rizzo S, Barnett P, Scicluna BP, Bauce B, van den Hoff MJ, de Bakker JM, Tan HL, Valente M, Nava A, Wilde AA, Moorman AF, Thiene G, Bezzina CR: Myocyte necrosis underlies progressive myocardial dystrophy in mouse dsg2-related arrhythmogenic right ventricular cardiomyopathy. J Exp Med 2009;206:1787-1802.

-30 Behr ER, Dalageorgou C, Christiansen M, Syrris P, Hughes S, Tome Esteban MT, Rowland E, Jeffery S, McKenna WJ: Sudden arrhythmic death syndrome: familial evaluation identifies inheritable heart disease in the majority of families. Eur Heart J 2008;29: 1670-1680.

-31 Basso C, Czarnowska E, Della BM, Bauce B, Beffagna G, Wlodarska EK, Pilichou K, Ramondo A, Lorenzon A, Wozniek O, Corrado D, Daliento L, Danieli GA, Valente M, Nava A, Thiene G, Rampazzo A: Ultrastructural evidence of intercalated disc remodelling in arrhythmogenic right ventricular cardiomyopathy: an electron microscopy investigation on endomyocardial biopsies. Eur Heart J 2006;27:1847-1854. 